\title{
Management training in psychiatric practice
}

\section{J. Higgins, Sub Dean}

Management skills have always been important in psychiatry, perhaps more so than in any other specialty. The multidisciplinary and manpower intensive style of working requires the consultant, as leader of the clinical team, to plan, develop, run and even defend services. The practice of psychiatry is gradually changing with innovations in treatment and more abruptly with reorganisation of management in the Health Service. The introduction of general management can present difficulties but also brings opportunities, provided the consultant is knowledgeable about the role of managers, the pressures and constraints on them and how best to influence them.

Some psychiatrists are natural managers but even they need to have their skills honed. For most new consultants it is too late to try and learn management skills after appointment; specific training is required beforehand, certainly at senior registrar level and probably earlier.

Before each alternate meeting of the Education Committee an Open Forum is held, at which invited speakers talk on a topic of educational interest for psychiatrists. On 6 March 1989 the subject was Management Training in Psychiatry. The three speakers were Professor Roger Dyson, Director of Adult and Continuing Education and of the Clinical Management Unit, University of Keele; Dr Stephen Harrison, Senior Lecturer in Policy Studies, Nuffield Institute for Health Services Studies, University of Leeds; Mr Lional Joyce, Unit General Manager, St Nicholas Hospital, Newcastle upon Tyne, and each agreed to provide a précis of his presentation for publication in the Psychiatric Bulletin.

\section{Management training for senior registrars}

Roger Dyson, Director of Adult and Continuing

Education at the University of Keele and

Director of the Clinical Management Unit

The University of Keele provides a programme of two-day single specialty management courses for senior registrars in association with the Royal ColColleges of Psychiatrists, Pathologists and Radiologists, the Association of Anaesthetists and the Royal College of Obstetricians and Gynaecologists. The programme and the clinical speakers are jointly agreed with the appropriate College.
At the present time off-site programmes in management training for doctors include:

(a) Short multi-specialty senior registrar management courses run at regional level by the Regions themselves.

(b) Short single-specialty programmes of the type run at Keele.

(c) Somewhat longer skills training programmes in a variety of venues but far less numerous because of their cost and because of the investment of clinical time away from work. They are invariably multi-professional.

(d) There is also now a small but growing number of part-time award bearing courses at Diploma and MBA level for senior registrars and consultants. The only MBA that is generic to the health care industry is the MBA in Health Planning and Management run by the Centre for Health Planning and Management at the University of Keele. This is now in its third year and has good clinical recruitment.

Each of these types of provision should be complementary rather than competitive. At different stages within a medical career each is appropriate for some doctors. The basic management training programme should be available to all senior registrars approaching their first consultancy whereas an MBA will only ever be of value to those considering an important and more long term commitment to management within their career.

The Keele programme is single specialty in order to allow senior registrars to concentrate in more depth upon the specific management challenges and choices that face their specialty. It focuses upon the key information necessary to tackle the first year in a consultant post.

The programme distinguishes between clinical management and resource management. Clinical management refers to the management of the individual patient, the management of a waiting list and the management of the wider multidisciplinary clinical team or network that centres upon the care of the individual patient. Resource management refers to all those non-clinical aspects of management which are involved in assembling buildings, equipment, personnel and finance to ensure that consultants are able to deliver appropriate treatment for their patients.

Although not appropriate to, e.g., the diagnostic specialties of pathology and radiology, the concern with clinical management is of crucial importance to psychiatrists. Half of the Keele programme is given 
to this subject and includes three contributions from consultant psychiatrists and additional ones from a clinical psychologist, a psychiatric nurse and a psychiatric social worker. Positive and able members of the non-medical specialties are selected in order to present a competent image of each profession. Senior registrars are able to consider their approach to nonmedical clinical colleagues and to clinical teams in the light of these contributions. In this setting the special problems of teams that straddle local authority and health authority employment can be better identified and discussed.

The core analytical content of the clinical management input deals with the issues of decision making in clinical teams and looks at alternative decision making models. The programme allows for a more in-depth consideration of alternatives and, for example, a discussion of the leadership model will concentrate upon appropriate styles of leadership in psychiatric settings. This work centres upon both diagnosis and treatment and includes consideration of the changing patterns of GP referrals. The presence of an additional session for a GP contribution to the programme is under active consideration.

\section{Challenges for the future}

The programme grows and changes in response to the current challenges facing psychiatry. Current challenges include:

(a) The continued transference from hospital to community is constantly changing the membership of clinical teams and networks and the pattern of clinical decision making. The interrelationship between the two is of crucial importance for psychiatrists developing new patterns of service.

(b) The new circular PL/CMO(89)1 Medical Responsibility in NHS Hospitals and Community Services for Mentally Ill and Mentally Handicapped People, changes the traditional view of the consultants' role outlined at the beginning of the NHS as "overall clinical responsibility" to one of "medical responsibility". Medical staff may see this change as being purely semantic but non-medical professions see it as a major change in their role and status and some have even argued that it is a move towards putting psychiatry outside the ringfence of medicine. It is therefore necessary to secure a very positive medical view of the circular and to consider working interpretations which do not undermine that ultimate medical responsibility.

(c) The resource management initiative in the NHS has so far concentrated upon surgical and related specialties and psychiatric services have been excluded. One consequence of this initiative will be to identify appropriate costs for each item of care and in the longer term will create pressures for appropriate funding as the clinical volume of work grows. Mental illness and mental handicap services have always tended to receive a block allocation within which to meet a growing volume of demand and such resource management initiatives could now be of value for psychiatry.

(d) This list would not be complete without a reference to the White Paper although the exact extent to which this influences the syllabus of future management programmes has still to be determined.

The resource management aspects of the Keele programme involve contributions from general management, financial management and from a Regional Medical Officer. These are both to provide a resource context for the study of clinical management and to create opportunities for senior registrars to question these officers about the management and development of their service. Crucially, they consider medical advisory committee machinery, and the planning process and the opportunities for psychiatrists to make effective contributions to that planning process.

\section{The context for management education in psychiatry}

STEPHEN HARRison, Senior Lecturer in Policy Studies, University of Leeds, Nuffield Institute for Health Services Studies

From an author who makes a major part of his living from providing management education for doctors ${ }^{1}$ the reader is entitled to a justification for the claim that such education is necessary at all. That is the purpose of this short note, which also serves to provide a context for Professor Dyson's and Mr Joyce's remarks about the content of management education in psychiatry.

Before the Griffiths changes of 1984-86, it was possible to regard management education for doctors as an option. Quite simply, and with some exceptions, health service managers could be regarded as acting on doctors' behalf. Empirical research ${ }^{2}$ into pre-Griffiths NHS managers' behaviour shows it to have been 'diplomatic' in character; rather than being the proactive, consumer-orientated, all-powerful actor found in the pages of popular management textbooks, he or she was more concerned to smooth out internal conflicts and to provide facilities for professionals to get on with their work.

No wonder then that the BMA was so alarmed at the prospect of general management: 